\title{
"Obscure" Appendiceal Orifice Polyps Can Be Challenging to Identify by Colonoscopy
}

\author{
Afshin Amini ${ }^{\mathrm{a}} \quad$ Elliot Koury ${ }^{\mathrm{a}} \quad$ Zahra Vaezi $^{\mathrm{b}} \quad$ Amirsina Talebian $^{\mathrm{a}}$ \\ Elie Chahlaa, \\ aDepartment of Medicine, St. Luke's Hospital, Chesterfield, MO, USA; \\ bDepartment of Medicine, Zahedan University of Medical Sciences, Zahedan, Iran; \\ 'Division of Gastroenterology and Hepatology, Department of Medicine, St. Luke's \\ Hospital, Chesterfield, MO, USA
}

\section{Keywords}

Obscure $\cdot$ Appendiceal orifice polyps $\cdot$ Colonoscopy

\begin{abstract}
The primary purpose of screening colonoscopy is the detection and subsequent removal of precancerous polyps. However, effective recognition of appendiceal lesions with a standard endoscope is often challenging and is limited to the base of the cecum and appendiceal orifice. The majority of appendiceal polyps are found incidentally following an appendectomy, though rarely they may be discovered during a colonoscopy. Despite being visualized by colonoscopy, most of these polyps are generally referred for surgical resection. The risk of developing carcinoma in patients with appendiceal polyps is likely similar to that of other colonic polyps, so it is essential for the endoscopist to examine and visualize the appendiceal orifice thoroughly. Various techniques are available to the endoscopist that can increase the accuracy of colonoscopic evaluation. These include luminal inflation and deflation, looking behind and pressing haustral folds, and repetitive passage of the scope over poorly visualized areas. To our knowl-
\end{abstract}




\section{Case Reports in Gastroenterology}

Case Rep Gastroenterol 2020;14:15-26

DOI: $10.1159 / 000505482$

(c) 2020 The Author(s). Published by S. Karger AG, Base www.karger.com/crg

Amini et al.: "Obscure" Appendiceal Orifice Polyps Can Be Challenging to Identify by Colonoscopy

edge, only 3 cases have been reported in the literature describing the discovery of obscure appendiceal polyps using colonoscopic techniques. Here we describe three cases of appendiceal orifice polyps missed on initial visualization but subsequently protruded into the cecum following prolonged examination and gentle deflation in the cecum. The endoscopist should consider the possibility of an appendiceal neoplasm, especially if other colonic polyps have been found. Endoscopists should spend adequate time examining the cecum during a screening colonoscopy to expose and thoroughly examine the appendiceal region.

(C) 2020 The Author(s)

Published by S. Karger AG, Basel

\section{Introduction}

The term polyp refers to a mucosal protrusion and is a clinically valuable histopathological label to the pathologist. Polyps may be described as inflammatory, hamartomatous, serrated (hyperplastic), or adenomatous [1]. It is well known that colorectal cancers arise more commonly from adenomatous polyps, which have three histologic variants. These are the tubular, tubulovillous, and villous adenomatous variants. Adenomas can be categorized based on their gross appearance on endoscopy. They may be described as pedunculated, sessile, flat, depressed, or excavated. Generally, adenomatous polyps are asymptomatic and are usually detected during screening colonoscopy [2].

Visualization and removal of precancerous polyps are essential goals of screening colonoscopy, although detection of polyps over poorly visualized areas such as appendix can be challenging. Endoscopic recognition of appendiceal lesions is limited to the base of the cecum and appendiceal orifice. The appendiceal orifice is described in endoscopy literature as having a "crow's foot" appearance and is located at the junction of the three taenia coli, at the pole of the cecum [3]. Furthermore, it is, along with the ileocecal valve, the most reliable landmark for establishing cecal intubation [4].

Benign appendiceal polyps are rare and usually found incidentally during autopsy or surgery [5]. The incidence of these polyps on autopsy was reported to be between $0.004 \%$ and $0.08 \%$ [6]. The discovery of appendiceal polyps during colonoscopy is uncommon, and the current literature on this subject is very limited. However, for correct recognition of appendiceal pathologies, the endoscopist must be aware of abnormal features of the appendiceal orifice [7].

Here we describe three cases of appendiceal orifice polyps missed on initial visualization but which later protruded into the cecum following prolonged examination and mild suction at the orifice of the appendix. Successful complete polypectomy at the time of endoscopy was performed in all cases. In all these cases, the ileocecal valve intubation was successful and the examined terminal ileum was normal. 


\section{Case Reports in Gastroenterology}

\begin{tabular}{l|l}
\hline Case Rep Gastroenterol 2020;14:15-26 \\
\hline DOI: 10.1159/000505482 & $\begin{array}{l}\text { @ 2020 The Author(s). Published by S. Karger AG, Basel } \\
\text { www.karger.com/crg }\end{array}$
\end{tabular}

Amini et al.: "Obscure" Appendiceal Orifice Polyps Can Be Challenging to Identify by Colonoscopy

\section{Cases}

Case 1

A 49-year-old African-American female with a significant past medical history of hypertension, anxiety, and irritable bowel syndrome was referred by her family physician for screening colonoscopy. Colonoscopy revealed a 3-mm sessile polyp in the rectosigmoid colon, and the polyp was tubular adenoma. Initial visualization of appendiceal orifice did not show any abnormalities (Fig. 1a). However, after deflation of the cecum, a 6-mm pedunculated polyp was seen protruding into the cecal lumen (Fig. 1b). A standard polypectomy forceps was used to visualize the polyp better. A thin, slender stalk originating from within the appendiceal lumen was identified (Fig. 1c). The polyp was then resected completely using a snare polypectomy technique. The pathology of the resected polyp was a tubular adenoma (Fig. 1d).

\section{Case 2}

An 83-year-old male with a past medical history significant for acid reflux, diabetes, hypertension, and hyperlipidemia was referred by his primary care physician for colonoscopy due to a positive fecal immunochemical test. He was hemodynamically stable and laboratory tests were unremarkable. He has had no gastrointestinal symptoms. His last colonoscopy 9 years ago showed two sessile polyps in the cecum, which were removed, and the polyps were tubular adenoma. In the current presentation, colonoscopy demonstrated four sessile polyps varying in size from 3 to $5 \mathrm{~mm}$ in the sigmoid colon, which were all removed with a cold snare. Histopathologic examination revealed hyperplastic polyps. In addition, a 5-mm polyp was found beside the appendiceal orifice, which was removed by a hot snare. Pathology reported it as a hyperplastic polyp. Reduction of cecal luminal pressure led to the exposure of a sessile polyp at the appendiceal orifice (Fig. 2a, b), which was resected using a cold snare technique (Fig. 2c), and the polyp was tubular adenoma (Fig. 2d). Non-bleeding external and internal hemorrhoids were also found during retroflection.

\section{Case 3}

A 58-year-old male with a past medical history of gastroesophageal reflux disease was referred for a screening colonoscopy. Laboratory tests were unremarkable. Colonoscopy showed a 2-mm sessile polyp in the ascending colon, which was removed with cold biopsy forceps. The pathology of the resected polyp was a tubular adenoma. In initial visualization, the appendiceal orifice was normal (Fig. 3a). However, with thorough examination and decompression of the cecum, a 5-mm sessile polyp was protruding to the cecum (Fig. 3b). The polyp was removed with cold forceps (Fig. 3c). Histopathology examination revealed sessile serrated adenoma (Fig. 3d).

\section{Discussion}

The appendix derives embryologically from the cecum and is histologically similar to the colorectal tissues [8]. The resemblance of the embryologic appendix to the cecum may explain the $4.1 \%$ incidence of synchronous appendiceal neoplasia with colorectal cancer [9]. Additionally, studies reported an association of appendiceal epithelial lesions with synchronous 


\section{Case Reports in Gastroenterology}

Case Rep Gastroenterol 2020;14:15-26

DOI: $10.1159 / 000505482$

(c) 2020 The Author(s). Published by S. Karger AG, Base www.karger.com/crg

Amini et al.: "Obscure" Appendiceal Orifice Polyps Can Be Challenging to Identify by Colonoscopy

carcinoma of the colon. This was reported between 12 and $21 \%$ of cases presenting for colectomy [6,9-11]. Due to the similarity of the appendiceal mucosa to the colon, it is hypothesized that appendiceal adenocarcinomas may represent $1 \%$ of all colorectal malignancies [5].

Appendiceal adenocarcinoma was shown to arise from preexisting adenomatous lesions [6]. However, if appendiceal cancer does occur, it is more likely to present at a younger age. The average age of diagnosis is 58 years, compared to 72 years in colorectal cancer. Prognosis is also worse among patients presenting with appendiceal malignancy. One of the reasons for this is related to the higher propensity of appendiceal cancer to spread through the lymphatic system [12].

Appendiceal polyps are rare, but the risk of developing carcinoma is likely similar to that of other colonic polyps [13]. Therefore, early detection of precancerous appendiceal polyps is essential. Despite this, these polyps are usually discovered incidentally during surgery, especially when complications such as appendicitis or intussusception are present. 10\% of these polyps are detected incidentally by laparotomy in unrelated appendiceal procedures [14]. These polyps were reported in 0.004 and $0.08 \%$ of autopsies [4]. The most common histological type of appendiceal lesion described following an appendectomy is mucinous cystadenoma, although villous adenomas and adenomatous polyps can be found as well [14]. Of the appendiceal malignancies, the majority are carcinoid tumors, although $10-20 \%$ are represented by mucinous cyst-adenocarcinoma, adenocarcinoma, lymphosarcoma, paraganglioma, and granular-cell tumors [15].

Instead of relying on surgical detection of appendiceal polyps, colonoscopy can occasionally recognize these lesions. However, colonoscopy is operator-dependent, and some colonoscopists may miss more polyps than others. Three main measures can be used to evaluate an endoscopist's performance. The most reliable measurement is the adenoma detection rate, which is defined as the proportion of screening colonoscopies where at least one adenoma is detected. The current adenoma detection rate benchmarks are $20-25 \%$ or higher for male patients and $15 \%$ or higher for female patients. The second measure is the cecal intubation rate, which is the colonoscopist's ability to intubate the cecum in $90 \%$ or more of all examined cases. The third measure is the withdrawal time, which evaluates whether a colonoscopist has spent sufficient time to perform a thorough mucosal examination between intubating the cecum and removing the colonoscope from the patient. The current benchmark for withdrawal time is 6 min or more in examinations where no biopsies or polypectomies are performed [16].

Missing polyps in poorly visualized areas can decrease the quality assurance of screening colonoscopy, although detection of polyps over areas such as appendiceal lumen can be challenging due to the limitation of access with a standard endoscope. Endoscopic recognition of appendiceal lesions is rare and restricted to the base of the cecum and appendiceal orifice. However, for correct recognition of appendiceal pathologies, the endoscopist must be aware of abnormal features of the appendiceal orifice [5]. Neoplasms, intussusceptions, an inverted appendix, appendiceal endometriosis, vascular ectasia of the appendix, isolated Crohn's of the appendix, and foreign bodies are examples of unusual appendiceal pathologies which have been discovered during colonoscopy following visualization of the appendiceal orifice and have been reported in the literature [5].

Recently a retrospective study was performed evaluating 691 patients with appendiceal polyps that were recognized by colonoscopy. Histological evaluation of these polyps revealed 


\section{Case Reports in Gastroenterology}

Case Rep Gastroenterol 2020;14:15-26

DOI: $10.1159 / 000505482$

(c) 2020 The Author(s). Published by S. Karger AG, Basel www.karger.com/crg

Amini et al.: "Obscure" Appendiceal Orifice Polyps Can Be Challenging to Identify by Colonoscopy

that $38.3 \%$ were non-neoplastic compared to $61.6 \%$ that were neoplastic lesions. The neoplasms were noted as follows: $30.4 \%$ adenomas, $30.2 \%$ tubular, $2.4 \%$ tubulo-villous, $0.1 \%$ villous, $17.8 \%$ sessile serrated adenomas/polyps, $8.8 \%$ hyperplastic polyps, and $1.1 \%$ traditional serrated adenomas. $0.4 \%$ of adenomas contained high-grade dysplasia. They noted $0.1 \%$ leiomyomas and $0.8 \%$ cancers including $0.4 \%$ adenocarcinoma and $0.4 \%$ carcinoid tumors [17]. Furthermore, when appendiceal polyps occur, they are more likely to be in the proximal third as opposed to the distal appendix. The rate of identification of appendiceal polyps by colonoscopy is not satisfactory [18]. The discrepancy between the rate of discovery of proximal appendiceal polyps on appendectomy as compared to colonoscopy possibly can be explained by the limitations of evaluating the appendiceal lumen through standard endoscopy, the infrequency of appendiceal orifice polyps, and endoscopists who are unfamiliar with appendiceal orifice lesions [7].

The presence of obscure appendiceal polyps also contributes to this discrepancy. Rarely, polyps may be hidden within the appendiceal lumen itself and may sometimes show themselves after prolonged evaluation of the cecum. To our knowledge, only three cases of this phenomenon are reported in the literature. Green et al. [19] reported a case in which a normal cecum and appendiceal orifice were observed, but after several minutes in the cecum instructing observers how to enter the terminal ileum, suction triggered a polyp to protrude from the appendix into the cecum. This polyp was managed with a referral for appendectomy, and tubulovillous adenoma was confirmed on pathology [19]. Another case reported by Khawaja [20] noted a polyp that was intermittently protruding into the cecal lumen from the appendix. The polyp was successful removed with standard polypectomy technique and was identified as an adenomatous polyp [20]. Ruffolo and Daly [21] also reported a case of an obscure appendiceal polyp, which could only be visualized by deflation of the cecal lumen.

Here we have described three cases of appendiceal orifice polyps missed on initial visualization of the cecum but which later were detected after careful and thorough evaluation including deflation of the cecum. In all 3 cases, polyps were removed endoscopically. Table 1 summarizes and compares the characteristics of the aforementioned cases. Analysis of these 6 cases reveals that in 5 cases, synchronous colorectal polyps were noted in addition to the appendiceal lesion, and one case was not determined. Sessile polyps were the most common synchronous colorectal polyps. In 4 cases, the polyps were removed by snare technique, one case underwent appendectomy, and one case was not determined. In addition, all 6 cases were reported to be adenomatous polyp histologically. 2 cases were tubular adenoma, 2 cases were reported as villous, 1 case as serrated, and in 1 case, the histology was not determined.

Identification of these polyps is crucial, as histology, number, and size are important factors for interpreting the risk of progression to cancer and the timing of the subsequent surveillance colonoscopy. Low-risk adenomas are defined as one to two tubular adenomas smaller than $1 \mathrm{~cm}$. In low-risk individuals, the first surveillance colonoscopy should be performed in 5 to 10 years [22].

High-risk adenomas are defined as three or more adenomatous or tubular adenomatous polyps measuring equal or larger than $1 \mathrm{~cm}$, or adenomas with villous histology or high-grade dysplasia. Current guidelines recommend first surveillance colonoscopy to be done in 3 years for high-risk patients [23]. A prospective cohort study that included 15,935 patients has reported that the risk of colorectal cancer in patients with high-risk adenomas was 2.7 times more per year as compared to those without adenomas at 13 years of follow-up [24]. 


\section{Case Reports in Gastroenterology}

Case Rep Gastroenterol 2020;14:15-26

DOI: $10.1159 / 000505482$

(c) 2020 The Author(s). Published by S. Karger AG, Base www.karger.com/crg

Amini et al.: "Obscure" Appendiceal Orifice Polyps Can Be Challenging to Identify by Colonoscopy

Accordingly, it is essential for endoscopists to be aware of an obscure appendiceal polyp. Discovery of such polyps can prevent complications such as appendicitis and intussusception. Additionally, this may affect the timing of subsequent surveillance colonoscopy. Furthermore, the detection and removal of such polyps can decrease the risk of future appendiceal or colorectal cancer.

As previously discussed, appendiceal polyps that are discovered on colonoscopy are commonly referred for surgical resection. Size, Morphology, Site, Access (SMSA) is a scoring system that is used to grade the difficulty encountered during a polypectomy. According to this scoring system, appendiceal polyps are often classified as problematic polyps. The use of endoscopic techniques for resection of appendiceal polyps can be challenging due to the difficulty of accomplishing complete removal of the lesion and the higher risk for perforation of the cecum [25]. Despite this, most difficult polyps can be safely removed via an endoscopic approach in the hands of an experienced endoscopist. In a retrospective study of 131 patients with appendiceal orifice polyps who underwent endoscopic resection, 93.9\% of patients achieved complete resection. This study concluded that endoscopic resection of cecal polyps involving the appendiceal orifice is safe and effective in select patients [26]. In terms of the method of resection, a retrospective study was done by Hassab and Church [17] that examined 691 cases of appendiceal orifice polyps removed between 2000 and 2017. They noted that the most common method of excision was cold biopsy forceps (36.3\%), followed by a hot snare $(9.3 \%)$, cold snare (8.5\%), jumbo cold forceps (6.7\%), hot biopsy (6.8\%), and endoscopic mucosal resection/dissection (4\%). Recurrence was seen in $10.3 \%$ of patients. Furthermore, the incidence of recurrence, as well as the need for surgical intervention, were more common with polyps measuring more than $5 \mathrm{~mm}$ in size [17]. In a small exploratory study, Bronzwaer et al. [27] suggest that endoscopic full thickening resection of non-pedunculated polyps between 10 and $15 \mathrm{~mm}$ is feasible and is a minimally invasive approach when compared to radical resection.

The goal of screening colonoscopy is detection and resection of precancerous polyps. Discovery and removal of such polyps can prevent complications, affect the timing of subsequent surveillance colonoscopy, and decrease the rate of future cancer. Therefore, endoscopists should closely examine all luminal surfaces, including poorly visualized areas such as the appendiceal orifice. Some techniques are available to increase the accuracy of the endoscopic examination. These include luminal inflation and deflation, examination behind and pressing on the haustral folds, and repetitive passage over poorly visualized areas. As illustrated in our three cases, endoscopists should be aware that not all polyps are readily identifiable. The possibility of an appendiceal neoplasm should always be considered, especially if other polyps have been noted in the colon. Polyps of the appendiceal orifice can easily be missed on initial visualization. Therefore, it is essential to expose and fully examine the appendiceal orifice region during colonoscopy. We recommend a prolonged and thorough examination of this region along with alternating deflation and insufflation of the lumen to aid in the identification of these obscure and challenging lesions. 


\section{Case Reports in Gastroenterology}

\section{Statement of Ethics}

The authors have no ethical conflicts to disclose. These three patients gave permission of the data usage for case presentation.

\section{Disclosure Statement}

The authors declare that they have no competing interests.

\section{Funding Sources}

No funding was received for this article.

\section{Author Contributions}

Afshin Amini performed the literature review, assisted in the initial manuscript, performed revisions, and is the article guarantor. Elliot Koury, Zahra Vaezi, and Amirsina Talebian performed the literature review and assisted in the initial manuscript. Elie Chahla performed the colonoscopic procedures, performed revisions, and edited the manuscript. All authors read and approved the final manuscript.

\section{References}

1 Emil S, Najib H. Adenoma and Malignant Colorectal Polyp: Pathological Considerations and Clinical Applications. EMJ Gastroenterol. 2018;7(1):92-102.

2 Amersi F, Agustin M, Ko CY. Colorectal cancer: epidemiology, risk factors, and health services. Clin Colon Rectal Surg. 2005 Aug;18(3):133-40.

3 Rex DK. Still photography versus videotaping for documentation of cecal intubation: A prospective study. Gastrointest Endosc. 2000 Apr;51(4 I):451-9. https://doi.org/10.1016/S0016-5107(00)70447-0.

4 Cirocco WC, Rusin LC. Factors that predict incomplete colonoscopy. Dis Colon Rectum. 1995 Sep;38(9):9648.

5 Al Toma A. Colonoscopic Visualization of Benign Polyps in the Appendiceal Region. Gastroenterol Hepatol Open Access. 2016 Dec 15;5(6).

6 Wolff M, Ahmed N. Epithelial neoplasms of the vermiform appendix (exclusive of carcinoid). I. Adenocarcinoma of the appendix. Cancer. 1976 May;37(5):2493-510.

7 Khawaja FI. Diseases of the appendix recognized during colonoscopy. Saudi J Gastroenterol. 2002 May;8(2):43-52.

8 Lee FD. Pathology of the appendix. R. A. Williams and P. Myers. Chapman \& Hall, London, 1994. J Pathol. 1994;173(3):297-297.

9 Khan MN, Moran BJ. Four percent of patients undergoing colorectal cancer surgery may have synchronous appendiceal neoplasia. Dis Colon Rectum. 2007 Nov;50(11):1856-9.

10 Higa E, Rosai J, Pizzimbono CA, Wise L. Mucosal hyperplasia, mucinous cystadenoma, and mucinous cystadenocarcinoma of the appendix. A re-evaluation of appendiceal "mucocele". Cancer. 1973 Dec;32(6):1525-41.

11 Qizilbash AH. Mucoceles of the appendix. Their relationship to hyperplastic polyps, mucinous cystadenomas, and cystadenocarcinomas. Arch Pathol. 1975 Oct;99(10):548-55. 
Amini et al.: "Obscure" Appendiceal Orifice Polyps Can Be Challenging to Identify by Colonoscopy

12 Fitzgerald E, Chen L, Guelrud M, Allison H, Zuo T, Suarez Y, et al. Appendiceal Adenocarcinoma Pre senting as a Rectal Polyp. Case Rep Gastroenterol. 2016 Feb;10(1):24-9.

13 Williams GR, du Boulay CE, Roche WR. Benign epithelial neoplasms of the appendix: classification and clinical associations. Histopathology. 1992 Nov;21(5):447-51.

14 Aranha GV, Reyes CV. Primary epithelial tumors of the appendix and a reappraisal of the appendiceal "mucocele". Dis Colon Rectum. 1979 Oct;22(7):472-6.

15 Ruoff C, Hanna L, Zhi W, Shahzad G, Gotlieb V, Saif MW. Cancers of the appendix: review of the literatures. ISRN Oncol. 2011;2011:728579.

16 Azer SA. Challenges Facing the Detection of Colonic Polyps: What Can Deep Learning Do? Medicina (B Aires). 2019;55(8):473.

17 Hassab TH, Church JM. Appendix orifice polyps: a study of 691 lesions at a single institution. Int J Colorectal Dis. 2019 Apr;34(4):711-8.

18 Sanes S. Polyposis of the Vermiform Appendix. Arch Surg. 1942;44(5):912.

19 Green PH, Perry E, Curry WT. Colonoscopic diagnosis of an appendiceal villous adenoma. Gastrointest Endosc. 1992 Jul-Aug;38(4):522-3.

20 Khawaja FI. Colonoscopic removal of an appendiceal polyp. Saudi J Gastroenterol. 2002 Sep;8(3):93-5.

21 Ruffolo TA, Daly C. Identifying obscure appendiceal polyps: the "deflated lumen" technique [Commentary]. Gastrointest Endosc. 2006 Apr;63(4):704-5.

22 Winawer SJ, Zauber AG, Fletcher RH, Stillman JS, O'Brien MJ, Levin B, et al.; US Multi-Society Task Force on Colorectal Cancer; American Cancer Society. Guidelines for colonoscopy surveillance after polypectomy: a consensus update by the US Multi-Society Task Force on Colorectal Cancer and the American Cancer Society. Gastroenterology. 2006 May;130(6):1872-85.

23 Hassan C, Quintero E, Dumonceau JM, Regula J, Brandão C, Chaussade S, et al.; European Society of Gastrointestinal Endoscopy. Post-polypectomy colonoscopy surveillance: European Society of Gastrointestinal Endoscopy (ESGE) Guideline. Endoscopy. 2013 Oct;45(10):842-51.

24 Click B, Pinsky PF, Hickey T, Doroudi M, Schoen RE. Association of colonoscopy adenoma findings with longterm colorectal cancer incidence. JAMA. 2018 May;319(19):2021-31.

25 Tholoor S, Tsagkournis O, Basford P, Bhandari P. Managing difficult polyps: techniques and pitfalls. Ann Gastroenterol. 2013;26(2):114-21.

26 Song EM, Yang HJ, Lee HJ, Lee HS, Cha JM, Kim HG, et al. Endoscopic Resection of Cecal Polyps Involving the Appendiceal Orifice: A KASID Multicenter Study. Dig Dis Sci. 2017 Nov;62(11):3138-48.

27 Bronzwaer ME, Bastiaansen BA, Koens L, Dekker E, Fockens P. Endoscopic full-thickness resection of polyps involving the appendiceal orifice: a prospective observational case study. Endosc Int Open. 2018 Sep;6(9):E1112-9. 


\section{Case Reports in Gastroenterology}

Case Rep Gastroenterol 2020;14:15-26
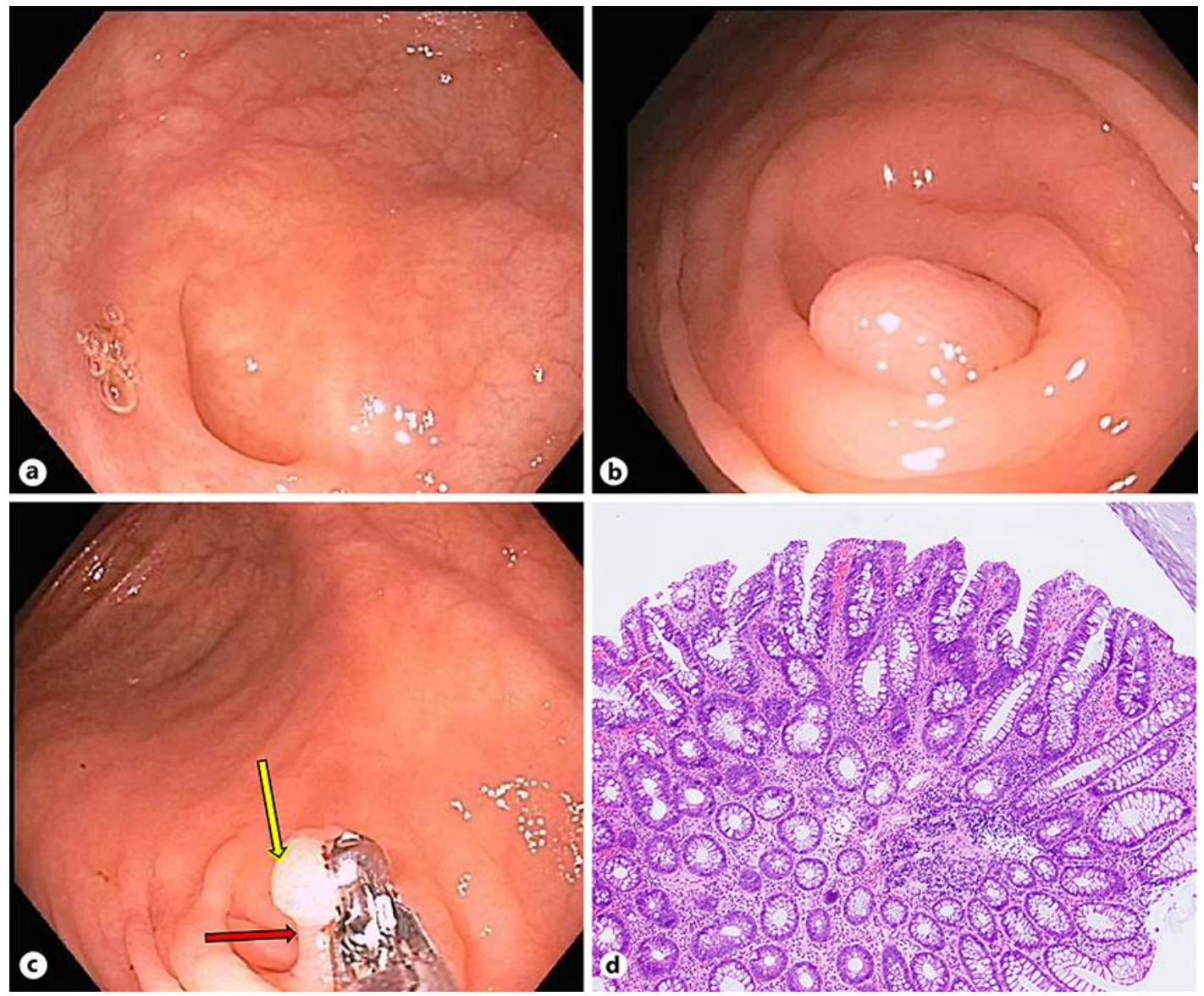

Fig. 1. a Appendiceal orifice. b A 6-mm polyp was found in the appendiceal orifice after air suctioning and mild decompression of the cecum. c Polyp fully exposed (yellow arrow) with a clear stalk (red arrow) using a biopsy forceps. $\mathbf{d}$ Tubular adenoma polyp (100x). 


\section{Case Reports in Gastroenterology}

\begin{tabular}{l|l}
\hline Case Rep Gastroenterol 2020;14:15-26 \\
\hline DOI: 10.1159/000505482 & $\begin{array}{l}\text { @ 2020 The Author(s). Published by S. Karger AG, Basel } \\
\text { www.karger.com/crg }\end{array}$ \\
\hline
\end{tabular}

Amini et al.: "Obscure" Appendiceal Orifice Polyps Can Be Challenging to Identify by Colonoscopy
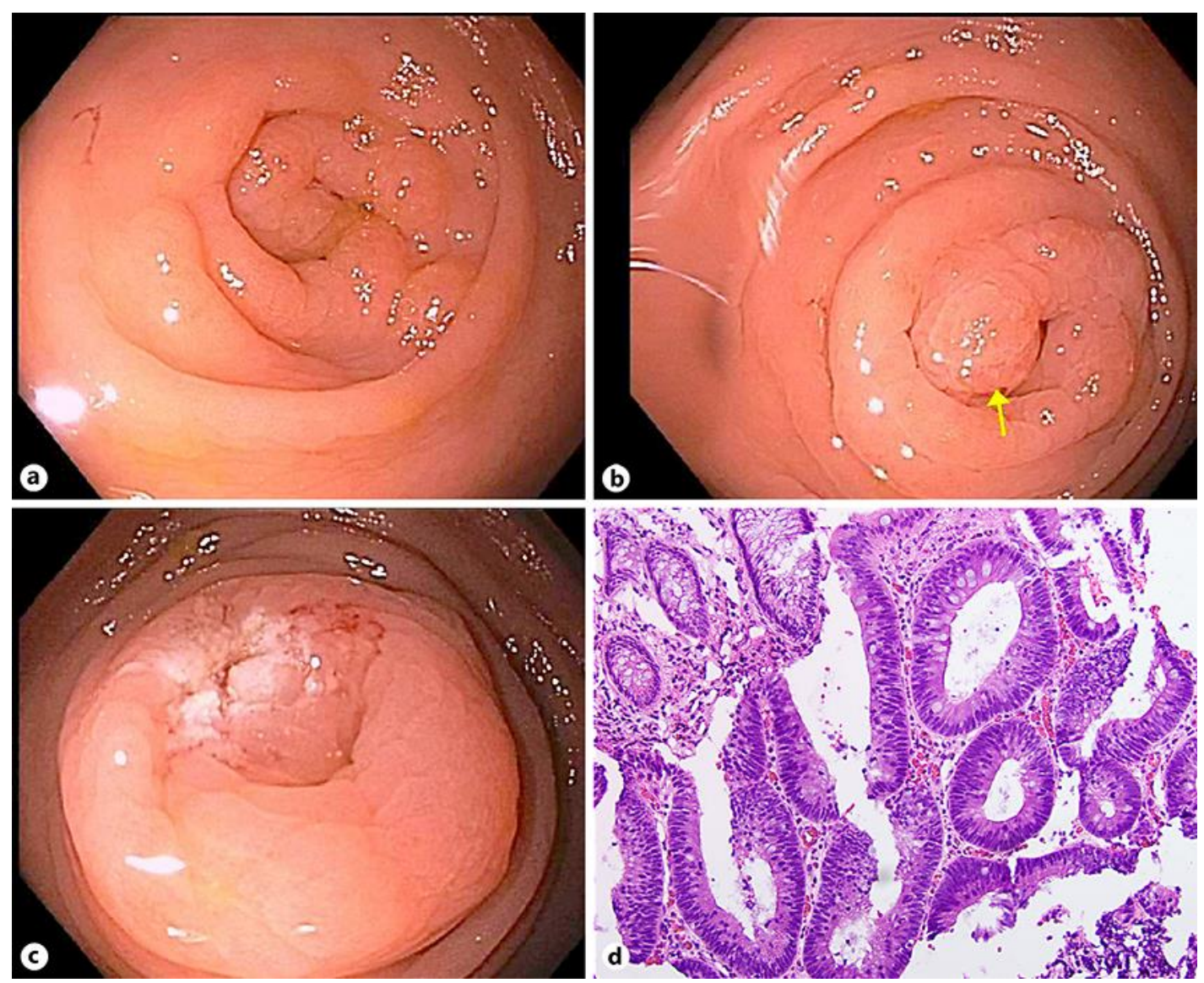

Fig. 2. a Appendiceal orifice. b Sessile polyp revealed after cecal deflation (yellow arrow). c Post polypectomy using a snare. $\mathbf{d}$ Tubular adenoma polyp (200×). 


\section{Case Reports in Gastroenterology}

Case Rep Gastroenterol 2020;14:15-26
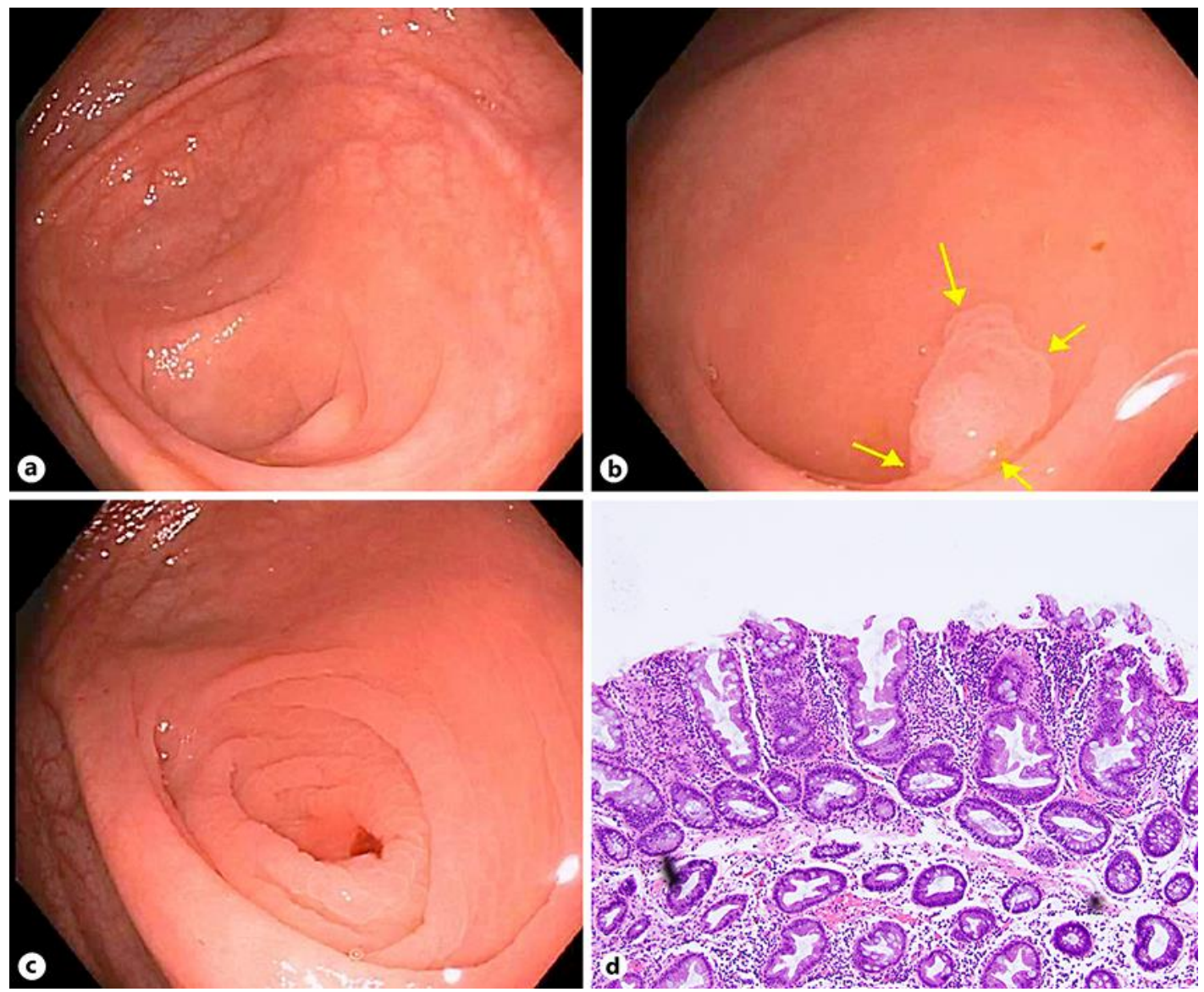

Fig. 3. a Appendiceal orifice appears normal. b A 5-mm sessile polyp was found at the orifice (yellow arrows) after careful examination. $\mathbf{c}$ Post polypectomy using cold forceps. $\mathbf{d}$ Sessile serrated adenoma polyp $(100 \times)$. 


\section{Case Reports in Gastroenterology}

Amini et al.: "Obscure" Appendiceal Orifice Polyps Can Be Challenging to Identify by

Colonoscopy

Table 1. Characteristics of the cases

\begin{tabular}{|c|c|c|c|c|c|c|c|c|}
\hline $\begin{array}{l}\text { Publication, } \\
\text { year }\end{array}$ & Ref. & $\begin{array}{l}\text { Age/ } \\
\text { gender }\end{array}$ & $\begin{array}{l}\text { Colonos- } \\
\text { copy } \\
\text { reason }\end{array}$ & $\begin{array}{l}\text { Colonoscopy } \\
\text { technique } \\
\text { over AO }\end{array}$ & $\begin{array}{l}\text { Features of } \mathrm{AO} \\
\text { polyp after } \\
\text { colonoscope } \\
\text { technique }\end{array}$ & $\begin{array}{l}\text { A0 polyp } \\
\text { management, } \\
\text { pathology } \\
\text { report }\end{array}$ & $\begin{array}{l}\text { Gross view AO } \\
\text { polyp after } \\
\text { appendectomy, } \\
\text { pathology report }\end{array}$ & $\begin{array}{l}\text { Colorectal polyps, pathology } \\
\text { report }\end{array}$ \\
\hline $\begin{array}{l}\text { Green et al., } \\
1992\end{array}$ & 19 & $80 / \mathrm{M}$ & Screening & $\begin{array}{l}\text { Prolonged } \\
\text { visualization } \\
\text { and cecum } \\
\text { suction }\end{array}$ & large polypoid & $\begin{array}{l}\text { Appendicectomy, } \\
\text { villous } \\
\text { adenomatous }\end{array}$ & $\begin{array}{l}\text { polypoid mass on } \\
\text { a stalk } 1 \mathrm{~cm} \text { from } \\
\text { the proximal } \\
\text { margin of the } \\
\text { appendix, tubulo- } \\
\text { villous adenoma }\end{array}$ & $\begin{array}{l}\text { Polyp was removed from the } \\
\text { sigmoid colon, ND }\end{array}$ \\
\hline $\begin{array}{l}\text { Khawaja, } \\
2002\end{array}$ & 20 & $76 / \mathrm{M}$ & $\begin{array}{l}\text { Guaiac } \\
\text { positive }\end{array}$ & $\begin{array}{l}\text { Prolong } \\
\text { visualization } \\
\text { of AO polyp }\end{array}$ & $\begin{array}{l}\text { Pedunculated } \\
\text { AO polyp } \\
\text { intermittently } \\
\text { protruding into } \\
\text { the cecal lumen }\end{array}$ & $\begin{array}{l}\text { Standard snare } \\
\text { polypectomy, } \\
\text { adenomatous }\end{array}$ & N/A & $\begin{array}{l}\text { Four polyps were noted in the } \\
\text { colon: } \\
\text { (1) A } 2.5 \times 1 \mathrm{~cm} \text { pedunculated } \\
\text { polyp in the sigmoid colon, } \\
\text { invasive adenocarcinoma } \\
\text { with the malignant cells } \\
\text { extending into the resected } \\
\text { stalk } \\
\text { (2) A } 0.5 \mathrm{~cm} \text { sessile polyp in } \\
\text { the distal transverse colon, } \\
\text { benign polyp } \\
\text { (3) A } 2 \times 1.5 \mathrm{~cm} \text { sessile polyp } \\
\text { in the hepatic flexure, benign } \\
\text { polyp } \\
\text { (4) A sessile polyp close to } \\
\text { margin of the AO, benign } \\
\text { polyp }\end{array}$ \\
\hline $\begin{array}{l}\text { Ruffolo and } \\
\text { Daly, } 2005\end{array}$ & 21 & $55 / \mathrm{M}$ & ND & Deflation & Sessile & $\begin{array}{l}\text { NR, villous } \\
\text { adenoma }\end{array}$ & ND & ND \\
\hline $\begin{array}{l}\text { Amini et al., } \\
\text { Case 1, } 2018\end{array}$ & & $49 / F$ & Screening & Deflation & $\begin{array}{l}\text { 6-mm } \\
\text { pedunculated } \\
\text { polyp }\end{array}$ & $\begin{array}{l}\text { Cold snare } \\
\text { polypectomy, } \\
\text { tubular adenoma }\end{array}$ & $\mathrm{N} / \mathrm{A}$ & $\begin{array}{l}\text { A } 3 \text {-mm sessile polyp in the } \\
\text { rectosigmoid, tubular } \\
\text { adenoma }\end{array}$ \\
\hline $\begin{array}{l}\text { Amini et al., } \\
\text { Case 2, } 2019\end{array}$ & & $83 / \mathrm{M}$ & $\begin{array}{l}\text { Positive } \\
\text { FIT }\end{array}$ & Deflation & $\begin{array}{l}\text { 6-mm sessile } \\
\text { polyp }\end{array}$ & $\begin{array}{l}\text { Cold snare } \\
\text { polypectomy, } \\
\text { tubular adenoma }\end{array}$ & N/A & $\begin{array}{l}\text { Five polyps were noted in the } \\
\text { colon: } \\
\text { (1) Four } 3-5 \text {-mm sessile } \\
\text { polyps in sigmoid colon, } \\
\text { hyperplastic polyps } \\
\text { (2) 5-mm cecal polyp, } \\
\text { hyperplastic polyp }\end{array}$ \\
\hline $\begin{array}{l}\text { Amini et al., } \\
\text { Case 3, } 2019\end{array}$ & & $58 / \mathrm{M}$ & Screening & Deflation & $\begin{array}{l}5 \text {-mm sessile } \\
\text { polyp }\end{array}$ & $\begin{array}{l}\text { Cold forceps } \\
\text { polypectomy, } \\
\text { sessile serrated } \\
\text { adenoma }\end{array}$ & N/A & $\begin{array}{l}\text { A } 2-m m \text { sessile polyp was } \\
\text { found in the ascending colon, } \\
\text { tubular adenoma }\end{array}$ \\
\hline
\end{tabular}

M, male; F, female; AO, appendiceal orifice; N/A, not applicable; ND, not determined; NR, not reported; FIT, fecal immunochemical test. 